\title{
WANGSALAN WARANGGANA WAYANG \\ DALAM KAJIAN SASTRA KARAWITAN
}

\author{
Purwadi \\ Fakultas Bahasa dan Seni, Universitas Negeri Yogyakarta \\ E-mail: hariwijaya04@yahoo.com
}

\begin{abstract}
Abstrak
Wangsalan adalah puisi Jawa yang menyampaikan pesan secara simbolik. Wangsalan dapat diklasifikasikan kedalam patriotism, percintaan, kerja sama, dan kerja keras. Nilai nasionalisme menggunakan istilah praja, negara, dan bangsa. Roman percintaan berhubungan dengan perasaan yang dinyatakan dengan tanda kata-kata. Sistem kerja sama dalam budaya Jawa bertujuan untuk mendapatkan harmonisasi sosial. Dorongan kerja keras dinyatakan dengan wangsalan, agar setiap orang berhasil hidupnya.
\end{abstract}

Kata kunci: wangsalan, tanda, hidup.

\author{
WANGSALAN WARANGGANA WAYANG \\ IN THE STUDY OF KARAWITAN LITERATURE
}

\begin{abstract}
Wangsalan is Javanese poetry that conveys message simbolically. It can be classified in patriotism, love, cooperation, and hardwork. The nationalism value employs the terms praja, negara, bangsa. The love romance is connected with feelings expressed in signs of words. The cooperation system in Javanese culture is aimed at creating social harmony. The spirit of hard work is written in wangsalan, so that everyone can be successful in life.
\end{abstract}

Keywords: wangsalan, sign, life

\section{PENDAHULUAN}

Penyajian kesusasteraan Jawa dalam bentuk tulis sesungguhnya bervariasi. Pengarang Jawa memiliki kesukaan dan ketrampilan yang berbeda. Mereka menuangkan buah pikir terkait dengan latar pekerjaan, pergaulan, status, tradisi dan tugas yang harus diemban.

Bahasa kesusasteraan yang bersifat simbolik, penuh perlambang, terdapat teka-teki serta perumpamaan menunjukkan jiwa penulis. Kata-kata yang digunakan, aliterasi, disonansi, konvensi juga dapat menunjukkan kedudukan seorang pengarang. Gaya bahasa dalam ragam sastra Jawa itu bertingkat-tingkat. Demikian pula cara memahami tentu berjenis-jenis pula. Masing-masing bentuk mempunyai tujuan untuk mengungkapkan gagasan estetis.
Pementasan wayang memiliki usia panjang yang dapat ditinjau secara historis (Hersapandi, 1999 : 15). Wangsalan merupakan bentuk karya sastra Jawa yang kerap dibawakan oleh para waranggana wayang purwa. Waranggana disebut pula pesindhen yang bertugas untuk melagukan tembang-tembang iringan wayang. Sesuai dengan adegan cerita, wangsalan berguna untuk memberi karakter pentas wayang. Syair-syair wangsalan dipilih untuk menambah keagungan pementasan.

\section{Semangat Bela Negara}

Rasa nasionalisme perlu digalakkan untuk para generasi muda. Nilai kebangsaan itu dalam wangsalan waranggana wayang diungkapkan 
dengan mengutip kata-kata negara, praja, bangsa, dan nusa. Isinya tentang watak luhur untuk mengutamakan kepentingan umum daripada kepentingan pribadi atau golongan.

Cinta tanah air dan bangsa berguna untuk membentuk sifat patriotik. Tokoh-tokoh pewayangan seperti Kumbakarna, Adipati Karna, dan Patih Suwanda penuh dengan keteladanan, bahkan mungkin tokoh dalam Serat Tripama itu sangat dipuja oleh orang Jawa. Anjuran untuk membela tanah air diutamakan, dihargai dan dijunjung tinggi.

Pentas Wayang Orang "Ngesti Pandowo" selalu menggunakan sistem manajemen yang baik, termasuk dalam hal penyajian gendhinggendhing-nya (Sujarno, dkk, 2016 : 80). Wangsalan yang digunakan untuk mengiringi adegan yang gagah, tegap, semangat, berwibawa dijumpai dalam gendhing srepeg. Suasana megah, mewah, meriah terbangun. Suara waranggana yang merdu berselaras dengan instrumen gamelan. Diksi wangsalan makin menggugah nilai kepahlawanan. Daya pikat sajian wangsalan ini sungguh meresap dalam hati. Sikap bela negara dihayati sebagai ungkapan yang terpuji.

Jarwa nendra narendra yaksa Ngalengka Mumpung tresna dadya srana njunjung bangsa

Jarweng janma janma kang koncatan jiwa Wong prawira mati alabuh nagara

Nata dewa praja retna pra pangarsa nggegurua marang janma kang utama

Makna wangsalan di atas terkait dengan pengabdian kepada bangsa dan negara. Bekal pengabdian tersebut berupa keutamaan. Abdi negara perlu ilmu pengetahuan yang memadai.

Jarwa mudha mudhane sang prabu Kresna mumpung anom ngudia srananing praja.

Tawas pita darpa driya wisnu garwa Murweng gita karsa dalem sri narendra.
Para pemuda hendaknya belajar ilmu tata negara. Kelak siap menggantikan estafet kepemimpinan. Itulah pesan wangsalan di atas.

Mardi basa wengku salu welut wisa Karya wulang wawatone wong ngawula

Tambah cacah sembilang taji sapasang Mangka peling marang wadya kang leleda.

Empu sendhang ari prabu Gendrayana

Supayantuk sudarsana kang prayoga.

Sisa brama arane empu Mandura

Wong ngawula ing ratu nora ngrekasa.

Pakem praja bubuhane saniskara

Angger nungkul anglakoni wajibira.

Arti yang dikandung dalam wangsalan tersebut meliputi tata krama mengabdi pada negara. Keutamaan seorang abdi negara yaitu turut serta menjaga keamanan dan ketentraman.

Wesi pita sekar wayah girinata

Sun cecadhang manunggaling bangsa kita.

Jangkah wuri emas jingga saupama

Tanpa mundur mrawasa angkara murka.

Barat madya sri maha prabu Pancala

Wong kepengin ngestu pada rajaputra.

Magut pala rawining kang ringgit purwa

Kang pinethik lakone Jaka Pramana.

Kawi jiwa baladan kang tembung jawa

Atmajendra ing Pegelen prajanira.

Wangsalan di atas mengajarkan ilmu pengetahuan. Sejarah masa silam harus dipelajari. Di sana banyak ditemukan suri teladan yang baik.

Trahing nata nata kang dalem ing pura Den rumeksa mring gusti kang mengku praja. 
Daging palwa palgawa Anjani putra

Labuhana siti wutahing ludira.

Jarweng janma janma kang koncatan jiwa

Wong prawira mati ngungkebi nagara.

Jarwa seta seta brit kang suka seta

Ngudi tama srana sih tresna mring bangsa.

Dana lila lilane wong tilar wisma

Budi darma ambeging Narendra tama.

Jasa para leluhur diungkapkan dalam wangsalan di atas. Kewajiban generasi sekarang untuk melanjutkan gagasan agung. Para raja Jawa memberi keteladanan.

Bibis tasik taksaka kang mawa pada Haywa mundur kepengkok ing pancabaya.

Welut wisa sawung asli liyan praja Ywa ngresula dadya bantening nagara.

Mrecon gora penyu biru ing sarira Nora longka labuh bangsa toh jiwa.

Sifat prajurit utama rela berkorban. Jiwa patriotik dalam wangsalan tersebut menjadi sumber inspirasi. Perwira sejati selalu siap demi ibu pertiwi.

Jarwa nendra narendra yaksa Ngalengka Rukun tresna dadya srana njunjung bangsa.

Kawi sekar sekar pepujan Sri Kresna Trah kusuma ngudi wrih jayaning praja.

Pandam wisma golok lit gamaning kenya Mbiyantuwa mrih tata tentreming praja.

Palu gongsa gongsa kenong munya sora Labuh praja nora ilang sajegira.

Kala reta satriya ngungkuli jaya Sun bang ebang amisesa jroning pura.

Yaksa dewa, dewa dewi lir denawa Kala mudha, bangkit ambengkas durgama.
Mamet tirta tirta jawah jro katiga

Suka lila lebur luluh labuh praja.

Wangsalan tersebut memberi ajaran tentang cara mengelola pemerintahan. Pentas pedalangan kerap menampilkan heroisme seorang senapati. Kebijaksanaan Prabu Kresna bisa dijadikan contoh bagi sekalian abdi negara.

\section{Suasana Guyub Rukun}

Harmoni sosial diutamakan dalam masyarakat Jawa. Usaha untuk mewujudkan suasana guyub rukun diwujudkan dengan kerja bakti, gugur gunung, gotong royong, sambatan, rewang, bantu-binantu, buwuh, jagong, sarja, tilik, anjangsana. Kegiatan umum ini sudah menjadi tradisi yang mengarah pada keselarasan.

Ada ungkapan bersatu kita teguh, bercerai kita runtuh. Ungkapan yang menghargai rasa persatuan itu banyak dijumpai dalam wangsalan. Adegan pewayangan yang cocok untuk menuangkan gagasan kerukunan ini diselipkan dalam gendhing ladrang dan ketawang. Misalnya gendhing ketawang Subakastawa laras slendro pathet sanga digunakan untuk menyelipkan kata-kata kerukunan.

Musium Radyapustaka memiliki koleksi tentang kesenian Jawa (Rustopo, 2008 : 128). Gendhing ketawang sesuai dengan sikap lembut, pelan, penuh rasa hormat, tenang. Adegan pewayangan semakin tampak karakter. Apalagi adegan pertapan Saptaharga, maka gendhing ketawang Subakastawa mengajak para penonton untuk melakukan refleksi dan kontemplasi. Waranggana, wiyaga dan dalang bekerja sama dengan kolektif.

Asung jarwa pangundanging kadang wreda Mamrih suka sagung kang para miyarsa

Trahing nata, garwa risang Dananjaya Den prayitna, sabarang aywa sembrana.

Jarwa purwa tunggal basaning baskara Amiwiti sendhon sindhening pradangga 
Kawis pita kang lara kentaring toya

Den sumarah marang mring ywang sukma

Jarwa surya surya tengahing ancala

Srenging karsa mung nedya nyumurupana.

Taji wreksa wreksa pamupuhing wastra

Pari peksa sesendhon nyindheni gangsa

Asung jiwa dewa ndharat kekasihnya

Ywa sulaya sahiyeg sayuking karya.

Wangsalan di atas mengandung makna tentang kekaryaan. Masyarakat hidup rukun ketika memiliki produksi yang berlimpah ruah. Sejak dini anak dilatih dan dididik untuk berkarya secara kolektif.

Siwi kresna kresna parabe kang wrangka Kang sembada ambudi amrih utama.

Roning tanggung bebasan tanpa maleca Antepana budi temen anarima.

Roning tanggung bebaan tanpa maleca Antepane budi temen anarima

Kapal buntal maruta saliring wanda Sangek langka yen darbe pambenging cidra

Waseng praja warastra mungging sanjata Aja angkuh yen siniyan ing bendara.

Sopan santun dan tata krama diajarkan dalam wangsalan tersebut. Kerukunan masyarakat diwujudkan dengan sikap saling menghormati. Semua itu untuk menjaga suasana guyub rukun.

Kang kawarna sesembahaning jawata

Ganti iku sayektine trah bathara.

Sekar pisang pisang sesajine karya

Patut lamun linulutan mring sasama.

Sekar dhadhap dhadhap kang asung usada Tulungana dimen asri ing wardaya.
Kawis pita kang obah ing kali aya Aja wengsu arane Hyang Sukma.

Witing klapa kalapa kang masih muda Salugune wong mardi pikir raharja.

Sembah kalbu yen lumintu dadi laku Manggih hayu ayem tentrem kang tinemu.

Maksud wangsalan tersebut untuk mencapai ketentraman umum. Masing-masing warga bangsa perlu menjunjung tinggi nilai etika.

Wisma sanggan sanggan raga lumaksita Jroning suka kudu eling lan waspada.

Resmi krama satriya Girikastuba

Tingkah laku tetepa sinudarsana.

Perang cipta manembah wanci rahina

Rumeksoa mring luhuring asmanira.

Wogan tirta tirta wijil ngantariksa

Betahana lamun dhumawahing papa.

Tirta maya supaya anyar kinarya

Nenging driya tan anggalih amung sira.

Wohing aren pangucape janma nendra

Dipun eling, sabar nir ing dur angkara.

Wohing aren, putra resi sukapanca

Ngelingana, budi luhur lan utama

Wohing aren, raja dewa ing pratala

Ngelingana, jer basuki mawa beya

Balung janur, janur ingisenan boga

Widodoa, lepat saking sambikala.

Tapas aren, aren Arab wijilire

Tindak tanduk, nora tinggal tata krama

Bibis tasik tasik manda winor tirta

Maju mundur tangeh marem kang pinanggya. 
Cipta arda ardaning tyas mring sasama

Tyas susila nor roga ambeg jatmika.

Dengan mengkaji wangsalan di atas akan diperoleh pelajaran bahwa sopan santun bisa menjaga harmoni sosial. Dalam pewayangan unggah ungguh sangat diperhatikan. Hati yang bersih, rela, jujur menumbuhkan kepercayaan.

\section{Romantika Percintaan}

Manusia diberi anugerah oleh Tuhan berupa rasa cinta. Hubungan manusiawi ini berlaku sepanjang sejarah. Para ahli sastra menangkap peluang kreativitas ini dengan menuangkan romantika percintaan. Metafora dan gaya estetika sangat kaya dalam wangsalan waranggana wayang purwa.

Ungkapan estetis romantika percintaan menggunakan kata-kata tresna, asmara, gandrung dan welas asih. Paribasan, bebasan, saloka, parikan juga kerap mengungkapkan perasaan cinta, namun untuk wangsalan disajikan sangat halus. Kata-katanya tersembunyi terpilih, penuh cipta sasmita, perlambang, tanda dan harus pelan-pelan dalam memberi makna.

Nilai wangsalan cocok untuk mengiringi tradisi ritual Jawa (Suyami, 2017 : 146). Kemampuan pengarang dalam menyusun wangsalan dipengaruhi oleh pengetahuan, ilmu, pengalaman dan pergaulan. Pekerjaan pengarang turut serta menentukan diksi dan penyusunan kalimat wangsalan. Terlebih-lebih dengan aspek asmara, malah memerlukan penghayatan yang lebih mendalam.

Ujung jari balung randhaning kalapa

Winengkua sayekti dadya husada

Teja tirta atmaja nata Rahwana

Kekuwunging karya rujiting wardaya

Rubing garwa dhustha wasi jaladara Kaya ngapa agawe lara wiyoga.

Suteng nendra prajane Sri Bomantara Sun watara lamun sira darbe tresna.
Barat sirat pasewakan jro nayaka

Wus kawusa ing driya mung nganti sira.

\section{Lireng muka tinulada winursita}

Sun pepinta lejare marang wong priya.

Jarwa sarpa raja putra ing Mandura

Kang ginita kang priya anandhang brangta.

Anak muda bisa dilanda asmara. Tertarik pada lawan jenis seiring dengan usia pubertas. Hanya saja dalam wangsalan itu dijelaskan dengan penuh perlambang.

Jarwa roga pelabuhan nusa Jawa

Lawan rara Kemunyar putri Jepara.

Kayu rengka jalak geng pilis pita

Jalarane saking menco weh wiyoga.

Trah ngawirya werdining kang pulas carma Raden Jaka Pramana ingkang winarna.

Ngular dustha sakpada lit taleng kisma

Ingkang kena sambang tuturing kukila.

Perak tulya naga putra Widayaka

Temah linglung kalenglengan lara brangta.

Saji siwa arane basa nawala

Nadyan lamong nyalemong tanpa ukara.

Robe garwa dhustha weri jaladara

Kaya ngapa kang gawe lara wiyoga.

Rasa asmara yang bersemayam dalam hati tidak dapat dihindari. Wangsalan tersebut dengan jenaka, sopan, halus melukiskan suasana hati yang baru kasmaran.

Tanugangga narmada nir tirtanira Mendah baya ing benjang yen kasat mata.

Ken ing Daha kukila kulem sabawa

Kiraningsun dasih tan datan saronta.

Glagah pita pandaya mardi sarkara Ingsun pondhong kusuma mring pagulingan. 
Manisrengga satriya ing Lesan Pura

Setyanana yen laliya marang sira.

Lalu mangsa panusuling magut yuda Yen kasepa bantoni lara asmara.

Sandi setya rangkeping tuhu wicara Boten lamis dasihe den yektenana.

Wangsalan di atas mengutamakan tanggung jawab dalam olah asmara. Tidak boleh bermainmain dalam percintaan. Luka hati bisa sangat mendalam oleh salah kelola cinta. Orang hendaknya hormat pada percintaan.

\section{Dorongan Kerja Keras}

Ungkapan hemat pangkal kaya, rajin pangkal pandai hendaknya dihayati. Kerja keras merupakan usaha untuk mewujudkan kesejahteraan lahir batin. Produktivitas, kreativitas dan kualitas sebuah masyarakat ditentukan oleh etos kerja.

Lagu lancaran dalam wayang purwa yang berisi dengan keuletan, ketekunan, kerajinan kerap berkumandang. Waranggana melantunkan gendhing tropong bang memuat anjuran untuk bekerja keras. Liriknya penuh semangat, bergairah dan optimis. Bermula dari irama rangkap yang pelan sayup-sayup terdengar cukup nikmat, indah dan penuh sesak yang gagah dan bergairah.

Kesenian rakyat memang banyak mengangkat kisah kepahlawanan yang dapat digunakan sebagai suri teladan (Sumaryadi, 2018 : 184). Dorongan untuk tetap berkarya termasuk kegiatan mulia. Setiap warga yang bersedia berkarya tentu membuahkan peradaban cemerlang. Negara dapat berdiri kokoh karena memiliki kemandirian.

Janur gunung nengga dhawuhe sang nata Aja leren yen nyatane durung lebda.

Kawi dewa dewane wulan purnama Anjenthara lebda pasanging grahita.

Roning kamal putra resi Kumbayana Mumpung anom ngudia kawruh utama.
Seseorang membaca makna wangsalan di atas, akan sadar arti penting keberhasilan. Semua cita-cita butuh perjuangan. Usaha yang sungguh-sungguh mengantarkan sukses gemilang.

Kolik pria priyagung Anjani putra Tuhu eman wong anom wedi kangelan.

Tampang jala jala rowa pamot mina Temah nistha yen nekat nora sembada.

Pisang ganda mulwa rengka rinumpaka Den grahita aywa anggung kasangsaya.

Rambah karsa teteping kang patembaya Anggemana leluhur kang wus suwarga.

Banyak contoh orang sukses yang didahului kerja keras. Berakit-rakit ke hulu, lantas berenang-renang ke tepian. Maksudnya bersakit-sakit dahulu, bersenang-senang kemudian. Peribahasa itu sebagai renungan.

Wukir jaja jejuluking putra nata

Nora suwe Pangeran paring nugraha.

Bantu karya karya raga kang sarira

Rewangana lara lapa sawetara.

Jarweng kenya kenya kuciwa ing karna

Wani lara winalesing suka wirya.

Windon kesma cirine dapur curiga

Nadyan boten sinarwaya sapunika.

Kendhang alit, alite wara Sembadra

Mumpung mudha, den taberi lara lapa.

Witing klapa jawata ing ngarsapada

Salugune wong mudha gelem rekasa.

Masyarakat Jawa memiliki aktivitas yang bersifat simbolik (Timbul Haryono, 2004 : 69). Banyak pelajaran yang diperoleh dari wangsalan di atas. Usaha maksimal dengan dorongan kerja keras cocok dalam era kapan saja. Bangsa yang memiliki etos kerja tinggi 
memperoleh apresiasi dan kehormatan. Mereka akan hidup bahagia sejahtera.

\section{KESIMPULAN}

Pementasan wayang purwa sebaiknya memenuhi unsur tuntunan, tontonan dan tatanan. Pakem pedalangan disusun oleh pujangga Jawa dengan penuh kebijaksanaan hidup. Iringan wayang disajikan merupakan bentuk kristalisasi dan refleksi estetis.

Lagu-lagu iringan wayang yang berupa wangsalan itu cukup rumit. Penyusunan kalimat wangsalan membutuhkan renungan yang lama. Pengalaman, pengetahuan, pergaulan seseorang menambah bobot isi wangsalan. Ajaran luhur dibungkus dengan kata simbolik dan kalimat yang penuh keindahan.

Pelajaran utama pentas pewayangan dapat digunakan sebagai panduan dalam hidup berbangsa, bernegara dan bermasyarakat. Sedapat-dapatnya pelaku pedalangan mau menelusuri teks-teks klasik yang memuat seluk beluk wangsalan. Seni pakeliran pada masa depan akan semakin berbobot.

\section{DAFTAR PUSTAKA}

Hersapandi, 1999. Wayang Wong Sriwedari. Dari Seni Istana Menjadi Seni Komersial. Yogyakarta: Yayasan Untuk Indonesia.

Rustopo, 2008. Jawa Sejati. Yogyakarta: Ombak.

Sumaryadi, 2018. Nilai Estetika dalam Lakon Ketoprak. Yogyakarta: New Transmedia.

Sujarno, dkk. 2016. Wayang Orang Ngesti Pandowo (2001-2015). Kajian tentang Manajemen Seni Pertunjukan. Yogyakarta: Kementrian Pendidikan dan Kebudayaan. Suyami, 2017. Nilai Kearifan dalam Tradisi Ritual Jawa. Kajian Naskah Kuna Serat Cariyos Dewi Sri dan Serat Mumule. Yogyakarta: Dinas Kebudayaan Kabupaten Sleman.

Timbul Haryono, 2004. Teknologi Perunggu dalam Lintasan Kebudayaan Kuno. Yogyakarta: Pustaka Raja. 